UCRL-JC-124639

PREPRINT

\title{
Numerical Predictions of Dry Oxidation of Iron and Low-Carbon Steel at Moderately Elevated Temperatures
}

\author{
G. A. Henshall
}

This paper was prepared for submittal to Materials Research Society Fall Meeting

December 2-6, 1996

Boston, $M A$

November 1996

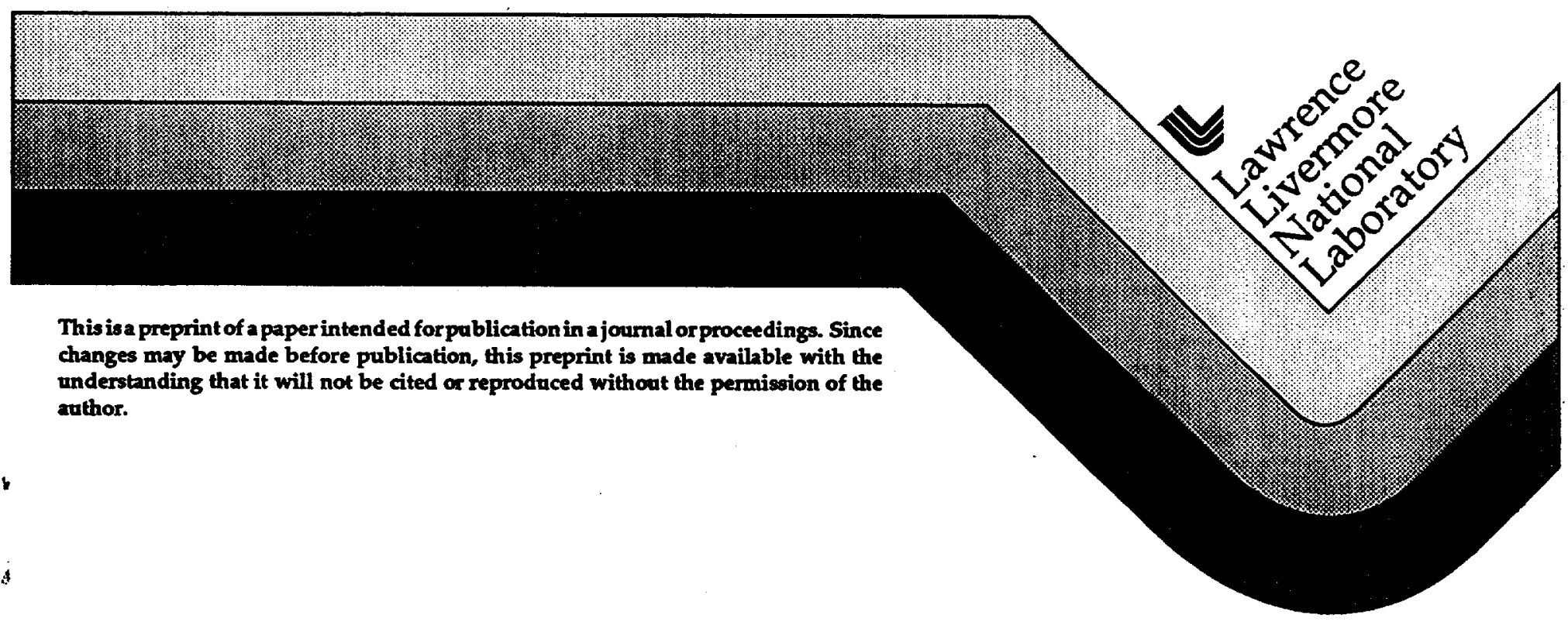




\section{DISCLAIMER}

This document was prepared as an account of work sponsored by an agency of the United States Government. Neither the United States Government nor the University of California nor any of their employees, makes any warranty, express or implied, or assumes any legal liability or responsibility for the accuracy, completeness, or usefulness of any information, apparatus, product, or process

disclosed, or represents that its use would not infringe privately owned rights. Reference herein to any specific commercial product, process, or service by trade name, trademark, manufacturer, or otherwise, does not necessarily constitute or imply its endorsement, recommendation, or favoring by the United States Government or the University of California. The views and opinions of authors expressed herein do not necessarily state or reflect those of the United States Government or the University of California, and shall not be used for advertising or product endorsement purposes. 


\title{
NUMERICAL PREDICTIONS OF DRY OXIDATION OF IRON AND LOW-CARBON
} STEEL AT MODERATELY ELEVATED TEMPERATURES

\author{
G. A. HENSHALL \\ Lawrence Livermore National Laboratory, L-355, Livermore, CA 94551.
}

\begin{abstract}
Wrought and cast low-carbon steel are candidate materials for the thick $(\mathrm{e} . \mathrm{g} .10 \mathrm{~cm})$ outer barrier of nuclear waste packages being considered for use in the potential geological repository at Yucca Mountain. Dry oxidation is one potential degradation mode for these materials at the moderately elevated temperatures expected at the container surface, e.g. $323-533 \mathrm{~K}\left(50-260^{\circ} \mathrm{C}\right)$. Therefore, numerical predictions of dry oxidation damage have been made based on experimental data for iron and low-carbon steel and the theory of parabolic oxidation. A numerical approach employing the Forward Euler method has been implemented to integrate the parabolic rate law for arbitrary, complex temperature histories. Assuming growth of a defectfree, adherent oxide, the surface penetration of a low-carbon steel barrier following 5000 years of exposure to a severe, but repository-relevant, temperature history is predicted to be only about $0.127 \mathrm{~mm}$, less than $0.13 \%$ of the expected container thickness of $10 \mathrm{~cm}$. Allowing the oxide to spall upon reaching a critical thickness increases the predicted metal penetration values, but degradation is still computed to be negligible. Based on these physically-based model calculations, dry oxidation is not expected to significantly degrade the performance of thick, corrosion allowance barriers constructed of low-carbon steel.
\end{abstract}

\section{INTRODUCTION}

Wrought and cast low-carbon steel are candidate materials for the thick (e.g. $10 \mathrm{~cm})$ outer barrier of nuclear waste packages (WPs) being considered for use in the potential geological repository at Yucca Mountain. Dry oxidation is one possible degradation mode for these materials at the moderately elevated temperatures expected at the container surface, e.g. 323-533 $\mathrm{K}\left(50-260^{\circ} \mathrm{C}\right)$. Due to the long times for which such barriers must remain intact (e.g. 5000 years), mathematical models are required with which to extrapolate the available short-time experimental data for the purpose of predicting container performance.

Stahl and McCoy [1] recently presented the following empirical equation to predict the penetration rate of a carbon steel barrier due to high temperature oxidation:

$$
p=1.787 \times 10^{5} t^{0.33} \exp (-6870 / T)
$$

where $p$ is the penetration depth in $\mu \mathrm{m}, t$ is the exposure time in years, and $T$ is temperature in Kelvins. Equation (1) predicts a negligible penetration of less than $0.02 \mu \mathrm{m}$ in 1000 years at the boiling point of water [2]. Equation (1) also was written in a differential form by McCoy [2] so that variable-temperature histories could be simulated. As in the derivation of Eq. (1), the activation energy was assumed to be independent of temperature in this analysis.

A somewhat different approach to the problem of predicting dry oxidation was taken in the present study. This approach was based on the theory of parabolic oxidation for iron and low-carbon steel, and employed a numerical integration technique to solve the resulting differential equation for arbitrary thermal histories. A simple method for estimating the effects of cracking or spalling of the oxide was also included. 


\section{DEVELOPMENT OF THE MODEL}

A variety of physical theories exist to describe the oxidation of metals at constant temperature [3]. In iron, a logarithmic relationship exists between oxide thickness and exposure time at low temperatures (i.e. near room temperature) and for oxide films less than about $0.1 \mu \mathrm{m}$ thick [4]. For oxide thicknesses of practical importance to WP degradation, however, both theoretical treatments and the available experimental data show that the dry oxidation of iron and low-carbon steels at moderately elevated temperatures $(293<T \leq 843 \mathrm{~K})$ is diffusion controlled, and therefore obeys a parabolic rate law if the temperature is constant [3-9].

In general, the parabolic oxidation of iron and low-carbon steel produces multi-layered scales due to the variable oxidation state iron. In order of proximity to the metal surface these are: $\mathrm{FeO}$ (wüstite), $\mathrm{Fe}_{3} \mathrm{O}_{4}$ (magnetite), and $\mathrm{Fe}_{2} \mathrm{O}_{3}$ (hematite). However, at temperatures below $843 \mathrm{~K}\left(570^{\circ} \mathrm{C}\right), \mathrm{FeO}$ is thermodynamically unstable, so only $\mathrm{Fe}_{3} \mathrm{O}_{4}$ and $\mathrm{Fe}_{2} \mathrm{O}_{3}$ form [3]. At these moderately elevated temperatures, the $\mathrm{Fe}_{3} \mathrm{O}_{4}$ layer is found to be much thicker than the $\mathrm{Fe}_{2} \mathrm{O}_{3}$ layer, at least for scales up to about $20 \mu \mathrm{m}$ thick [5]. Therefore, it was assumed in the present study that the oxide scale consists of only $\mathrm{Fe}_{3} \mathrm{O}_{4}$ at the temperatures of interest. This assumption significantly simplifies the model while providing predictions that are reasonably accurate, as shown in the next section.

In addition to the assumptions of parabolic growth (under isothermal conditions) and the presence of only magnetite, several other assumptions were made in developing the model. First, the $\mathrm{Fe}_{3} \mathrm{O}_{4}$ oxide was assumed to be $100 \%$ dense, consistent with observations for layers up to about $20 \mu \mathrm{m}$ thick [4,5,9]. Second, Arrhenius behavior with a constant activation energy over the relevant temperature range was assumed. As discussed later, this appears to be a reasonable approximation of the behavior for low-carbon steel oxidized in the $323-533 \mathrm{~K}\left(50-260^{\circ} \mathrm{C}\right)$ temperature regime. Third, it was assumed that oxidation occurs uniformly across the surface of the metal. Finally, the oxide was assumed to be adherent to the metal surface; a specific exception to this assumption is described later.

Mathematically, the parabolic increase in the thickness of a single-species oxide with increasing exposure time can be expressed [3]:

$$
\mathrm{d} x / \mathrm{d} t=k_{\mathrm{p}} / x
$$

where $x$ is the oxide thickness, $t$ is exposure time, and $k_{\mathrm{p}}^{\prime}$ is the parabolic rate constant. The temperature dependence of the oxidation rate is governed by the Arrhenius behavior of $k_{\mathrm{p}}^{\prime}$ :

$$
k_{\mathrm{p}}=k_{\mathrm{p}} \exp (-Q / R T)
$$

where $k_{\mathrm{p}}$ is a constant, $Q$ is the activation energy for the oxidation process, $R$ is the gas constant, and $T$ is absolute temperature. Literature values of $k_{\mathrm{p}}$ and $Q$ for iron and low-carbon steel are given in Table 1 . The values of $k_{\mathrm{p}}$ vary considerably, at least partly because the measurements were made using a variety of materials, surface treatments, and environments. In the parabolic regime and at the relatively low temperatures of $523-736 \mathrm{~K}\left(250-463^{\circ} \mathrm{C}\right), Q$ appears to be constant at about $104 \mathrm{~kJ} / \mathrm{mol}(25 \mathrm{kcal} / \mathrm{mol})$. This value is consistent with that for grain-boundary diffusion of $\mathrm{Fe}$ ions in $\mathrm{Fe}_{3} \mathrm{O}_{4}$ [4]. Table 1 shows that lower values of $Q$ have been measured at the higher temperatures of $673-853 \mathrm{~K}\left(400-580^{\circ} \mathrm{C}\right)$. The influence of a possible change in $Q$ at temperatures below $523 \mathrm{~K}$, which are most relevant to WP performance, is discussed in the next section.

Equations (2) and (3) can be easily integrated analytically for simple (e.g. constant) temperature histories. However, to perform the integration for arbitrary, complex thermal histories, such as those expected in the repository, a numerical approach employing the Forward 
Euler method [10] was implemented. Combining Egs. (2) and (3) and writing the result as a difference equation gives:

$$
\Delta x=\left\{(1 / x)\left[k_{\mathrm{p}} \exp (-Q / R T)\right]\right\} \Delta t
$$

where $\Delta x$ is the increase in oxide thickness during the time step $\Delta t$. Writing $\Delta x$ as

$$
\Delta x=x_{\mathrm{i}}-x_{\mathrm{i}-1},
$$

where the subscript " $i$ " denotes the current time step, Eq. (4) can be written

$$
x_{\mathrm{i}}-x_{\mathrm{i}-1}-\left\{\left(1 / x_{\mathrm{i}}\right)\left[k_{\mathrm{p}} \exp \left(-Q / R T_{\mathrm{i}}\right)\right]\right\} \Delta t=0 \text {. }
$$

This non-linear equation in the single unknown, $x_{1}$, can be solved using any standard method for solving non-linear equations in one variable. A bisection technique [10] was chosen because it is simple and robust. Also note that Eqs. (4)-(6) represent an implicit scheme for solving the differential equation (2). Therefore, while this method is unconditionally stable, the computed oxide thickness will depend on the time-step size. For this reason, convergence of the solution was confirmed by decreasing $\Delta t$ until the final $x$ values varied by less than a specified tolerance, typically $0.1 \%$, for a five-fold decrease in $\Delta t$.

For predicting the degradation of WPs, it is the metal penetration caused by oxidation, $p$, not the oxide thickness itself, that needs to be calculated. This can be accomplished by again assuming a fully dense $\mathrm{Fe}_{3} \mathrm{O}_{4}$ oxide forming on pure iron, and computing $p$ from the oxide thickness using:

$$
p=\left[\left(\rho_{0} / M_{0}\right)\left(M_{M} / \rho_{M}\right) N_{M}\right] x
$$

where $\rho_{0}$ and $\rho_{M}$ are the density of the oxide and the metal, $M_{0}$ and $M_{M}$ are the molecular or atomic weight of the oxide and the metal, and $N_{M}$ is the number of moles of metal atoms per mole of oxide ( 3 for $\mathrm{Fe}_{3} \mathrm{O}_{4}$ ). For simplicity, $\rho_{\mathrm{o}}$ and $\rho_{\mathrm{M}}$ were assumed to equal their room temperature values in the numerical calculations presented in the next section.

It is unrealistic to assume that a $10-\mathrm{cm}$ thick metal barrier will completely oxidize without cracking or spalling of the oxide layer. Such defects in the oxide decrease its protectiveness and increase the oxidation rate because fresh metal is exposed or a fast diffusion path for oxygen is created. Therefore, a conservative approach was taken to estimate the effects of mechanical defects in the scale. It was assumed that mechanical stresses build up in the oxide as its thickness increases, and that a critical thickness exists at which these stresses exceed the fracture strength of the oxide. Once this critical thickness, $x_{\mathrm{c}}$, is reached, the oxide is assumed to completely spall away, exposing the bare metal surface. At this point, the parabolic oxidation process begins as if no oxide had ever been present; i.e. $x=0$. Of course, the metal penetration does not return to zero when $x=0$, but continues to accumulate. In this case, the accumulated penetration, $P$, is computed from Eq. (8):

$$
P=\sum_{j=1}^{n} p_{j}
$$

where $n$ is the number of spall events or "cycles" and $p_{j}$ is computed from Eq. (7) for each cycle. While such a model is certainly over simplified, it provides a conservative way in which to treat defects in the scale. The use of such a conservative approach is justified later. 
Table 1. Oxidation of Iron and Carbon Steel at Moderately Elevated Temperatures.

\begin{tabular}{|c|c|c|c|c|c|c|}
\hline $\begin{array}{c}k_{\mathrm{p}^{\mathrm{a}}} \\
\left(\mathrm{cm}^{2} / \mathrm{s} \times 10^{5}\right)\end{array}$ & $\begin{array}{c}Q \\
(\mathrm{~kJ} / \mathrm{mol})\end{array}$ & $\begin{array}{c}T \\
(\mathrm{~K})\end{array}$ & $\begin{array}{c}x_{\max }^{\mathrm{b}} \\
(\mu \mathrm{m})\end{array}$ & Regimec $^{\mathrm{c}}$ & Alloy & Ref. \\
\hline \hline & 25.1 & $473-623$ & 0.05 & $\mathrm{~L}$ & $0.2-0.8 \% \mathrm{C}$ & 4 \\
\hline & 30.5 & $473-623$ & 0.1 & $\mathrm{~L}$ & $0.2-0.8 \% \mathrm{C}$ & 4 \\
\hline $0.7-1.7^{\mathrm{d}}$ & 104 & $523-623$ & 1.4 & $\mathrm{P}$ & $0.2-0.8 \% \mathrm{C}$ & 4 \\
\hline $0.02^{\mathrm{e}}$ & 104 & $541-736$ & 0.4 & $\mathrm{P}$ & $0.04 \% \mathrm{C}$ & 6 \\
\hline $0.03^{\mathrm{e}}$ & 102 & $541-666$ & 2 & $\mathrm{P}$ & $0.04 \% \mathrm{C}$ & 6 \\
\hline $2.5^{\mathrm{f}}$ & $34 / 106^{\mathrm{g}}$ & $673-923$ & 22 & $\mathrm{P}$ & $0.02 \% \mathrm{C}$ & 5 \\
\hline $0.02^{\mathrm{h}}$ & 72.4 & $673-823$ & 10.5 & $\mathrm{P}$ & Pure Fe & 7,8 \\
\hline 4.3 & & 773 & 15 & $\mathrm{P}$ & $0-0.99 \% \mathrm{C}$ & 9 \\
\hline
\end{tabular}

Notes:

a Representative or maximum values selected from the data provided

b Maximum oxide thickness observed, based on a fully dense layer of $\mathrm{Fe}_{3} \mathrm{O}_{4}$

${ }^{c} \mathrm{~L}=$ logarithmic, $\mathrm{P}=$ parabolic

d Measured at $573 \mathrm{~K}$

e Measured at $569 \mathrm{~K}$

f Measured at $723 \mathrm{~K}$

g $Q=106 \mathrm{~kJ} / \mathrm{mol}$ for $670 \leq T \leq 723 \mathrm{~K} ; Q=34 \mathrm{~kJ} / \mathrm{mol}$ for $723 \leq T \leq 853 \mathrm{~K}$

$\mathrm{h}$ Measured at $673 \mathrm{~K}$

\section{NUMERICAL RESULTS}

The validity of the assumptions used in developing the model, other than those associated with spalling, was tested by simulating literature data for the oxidation of iron and low-carbon steel at constant temperature. Figure 1 presents such data for both pure iron and for a lowcarbon steel. In both cases, the increase in oxide thickness with increasing exposure time is nearly parabolic over the range studied. These results support the hypothesis that the dry oxidation of these metals is diffusion controlled and can be modeled using Eq. (2). As shown in Fig. 1(a), the simulated oxidation rate is consistent with the data of Caplan and Cohen [5] for iron up to an oxide thickness of about $6 \mu \mathrm{m}$. The data of Boggs and Kachik [9] for 0.99\% C steel are simulated with nearly the same accuracy up to $x=16 \mu \mathrm{m}$, as shown in Fig. 1(b). The accuracy of the simulations shown in Fig. 1 suggests that the assumptions used to develop the model are reasonable for oxide thicknesses up to at least about $20 \mu \mathrm{m}$.

With the accuracy of the model confirmed for simple, constant-temperature conditions, predictions of oxidation were then made for complex, repository-relevant thermal histories. First, calculations were made using the WP surface temperatures calculated by Buscheck et al. [11] for a $27.3 \mathrm{~kg} \mathrm{U} / \mathrm{m}^{2}$ thermal loading. The computed oxide thickness and metal penetration values were very small, e.g. $x=20 \mu \mathrm{m}$ for 5000 years of exposure. Then, to increase the conservatism of the predictions, the temperatures calculated by Buscheck et al. were increased by $100 \mathrm{~K}$ for all exposure times. Figure 2(a) compares this "extreme" temperature history to a polynomial approximation that was used for the oxidation calculations. Based on the experimental data given in Table 1, values of $k_{\mathrm{p}}=4.3 \times 10^{-5} \mathrm{~cm}^{2} / \mathrm{s}$ and $Q=104 \mathrm{~kJ} / \mathrm{mol}$ were used in the oxidation predictions. The use of $k_{\mathrm{p}}=4.3 \times 10^{-5} \mathrm{~cm}^{2} / \mathrm{s}$ is conservative since this was the largest value indicated by the literature data. Figure 2(b) shows the resulting oxide thickness and metal penetration predictions for the case of a defect-free, adherent oxide. Note that the 
oxidation rate is not parabolic because the temperature is not constant. The metal penetration following 5000 years of exposure to this severe temperature history is predicted to be only about $0.127 \mathrm{~mm}$, less than $0.13 \%$ of the expected container thickness of $10 \mathrm{~cm}$. Using an empirical approach and assuming an adherent oxide, Stahl and McCoy [1] also predicted that very little metal penetration of carbon steel would occur due to dry oxidation under repository-relevant conditions.
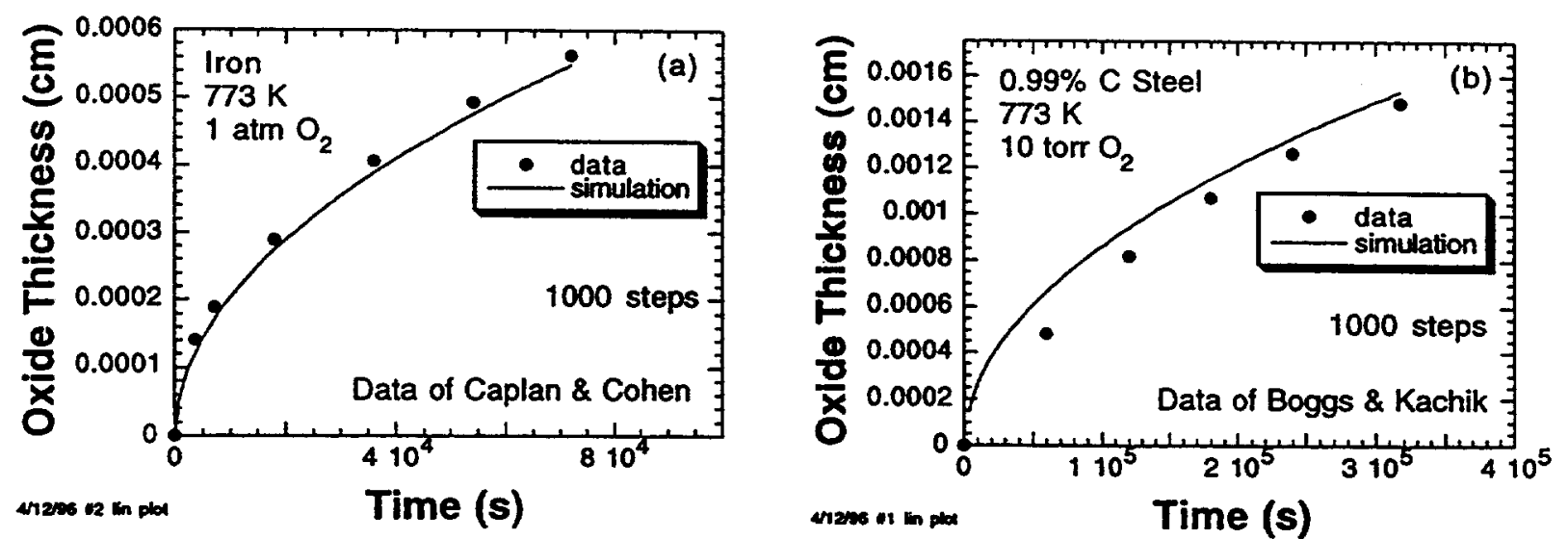

Fig. 1 Model simulations of isothermal oxide growth are compared with data for (a) iron oxidized at 773 $\mathrm{K}$ in 1 atmosphere of $\mathrm{O}_{2}$ [5] and (b) $0.99 \% \mathrm{C}$ steel oxidized at $773 \mathrm{~K}$ in a 10 torr $\mathrm{O}_{2}$ atmosphere [9].
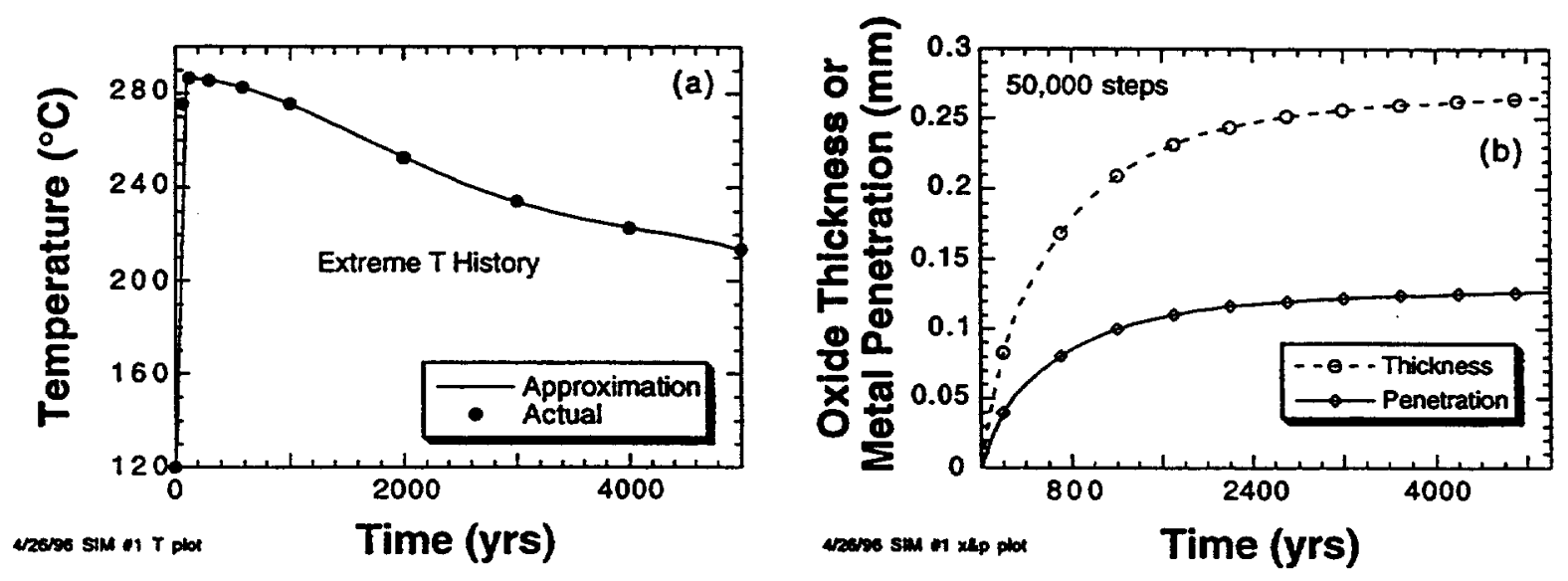

Fig. 2. (a) The "extreme" temperature history (solid circles) is compared to a polynomial approximation. (b) Corresponding model predictions of the oxide layer thickness and metal surface penetration histories assuming a fully dense, adherent oxide.

The data in Table 1 support the use of $Q=104 \mathrm{~kJ} / \mathrm{mol}$ for oxidation of iron and carbon steel at temperatures between 523 and $723 \mathrm{~K}\left(250-450^{\circ} \mathrm{C}\right)$. Since this value corresponds to that for grain-boundary diffusion of $\mathrm{Fe}$ ions in $\mathrm{Fe}_{3} \mathrm{O}_{4}$, it is likely that it will not decrease at the lower temperatures expected on WP surfaces, $323-533 \mathrm{~K}\left(50-260^{\circ} \mathrm{C}\right)$. Nevertheless, to evaluate the sensitivity of the predicted metal penetration on $Q$, the effect of a decreased activation energy at low temperatures was computed. The lowest value of $Q$ cited in the literature for parabolic oxidation at $T \leq 723 \mathrm{~K}$ is $72.4 \mathrm{~kJ} / \mathrm{mol}$ [7], Table 1 . Using this value together with $k_{\mathrm{p}}=4.3 \times 10^{-5}$ $\mathrm{cm}^{2} / \mathrm{s}$ [9], the calculations using the thermal history shown in Fig. 2(a) were repeated. The conservatism of this calculation must be emphasized: (1) the thermal history assumes temperatures $100 \mathrm{~K}$ higher than expected, (2) the activation energy equals the lowest value cited 
in the literature, which probably relates to much higher temperatures (Table 1), and (3) the preexponential constant, $k_{\mathrm{p}}$, is the largest that can be expected based on the available data. Despite this conservatism, the model predicts that $p=4.6 \mathrm{~mm}$, or only $4.6 \%$ of the expected container thickness, following 5000 years of exposure. Of course, it would be prudent to experimentally measure $Q$ in the temperature range of interest to confirm that some change in mechanism does not result in a $Q$ value significantly lower than that used here.

Defects in the oxide, such as cracking or spalling, would increase the metal penetration rate above that computed assuming a defect-free, adherent oxide layer. Using the approach described previously to account for such defects and the temperature history shown in Fig. 2(a), predictions of the surface penetration into iron or low-carbon steel were made. Values of the critical oxide thickness for spalling, $x_{\mathrm{c}}$, were chosen to be either $x_{\mathrm{c}}=0.02 \mathrm{~mm}$ or $x_{\mathrm{c}}=0.1 \mathrm{~mm}$. The former roughly corresponds to the maximum oxide thickness cited in literature studies [4-9] of fully dense, adherent oxide growth on iron and steel at the relevant temperatures (see Table 1). Since significant cracking or spalling was never observed in these studies, this value provides a reasonable lower limit on $x_{\mathrm{c}}$. The second value, $x_{\mathrm{c}}=0.1 \mathrm{~mm}$, was chosen arbitrarily to assess the influence of this parameter on the predictions. The values of $k_{\mathrm{p}}=4.3 \times 10^{-5} \mathrm{~cm}^{2} / \mathrm{s}$ and $Q=104$ $\mathrm{kJ} / \mathrm{mol}$ again were used in these calculations.

As shown in Fig. 3, the predicted metal penetration depths are larger than for the case of defect-free oxide growth, Fig. 2(b), but are still small. Therefore, even though the method used to treat defects in the oxide is very conservative, the model predicts that dry oxidation damage is minimal. For $x_{c}=0.02 \mathrm{~mm}$, Fig. 3(a) shows that $P$ is predicted to be approximately $1.7 \mathrm{~mm}$, or about $1.7 \%$ of the expected container thickness, following 5000 years of exposure to the extreme temperature history. Increasing $x_{c}$ to $0.1 \mathrm{~mm}$ decreases the predicted value of $P$ to approximately $0.35 \mathrm{~mm}$. In this case, the discontinuous rate of metal penetration caused by discrete spall events is clearly apparent.
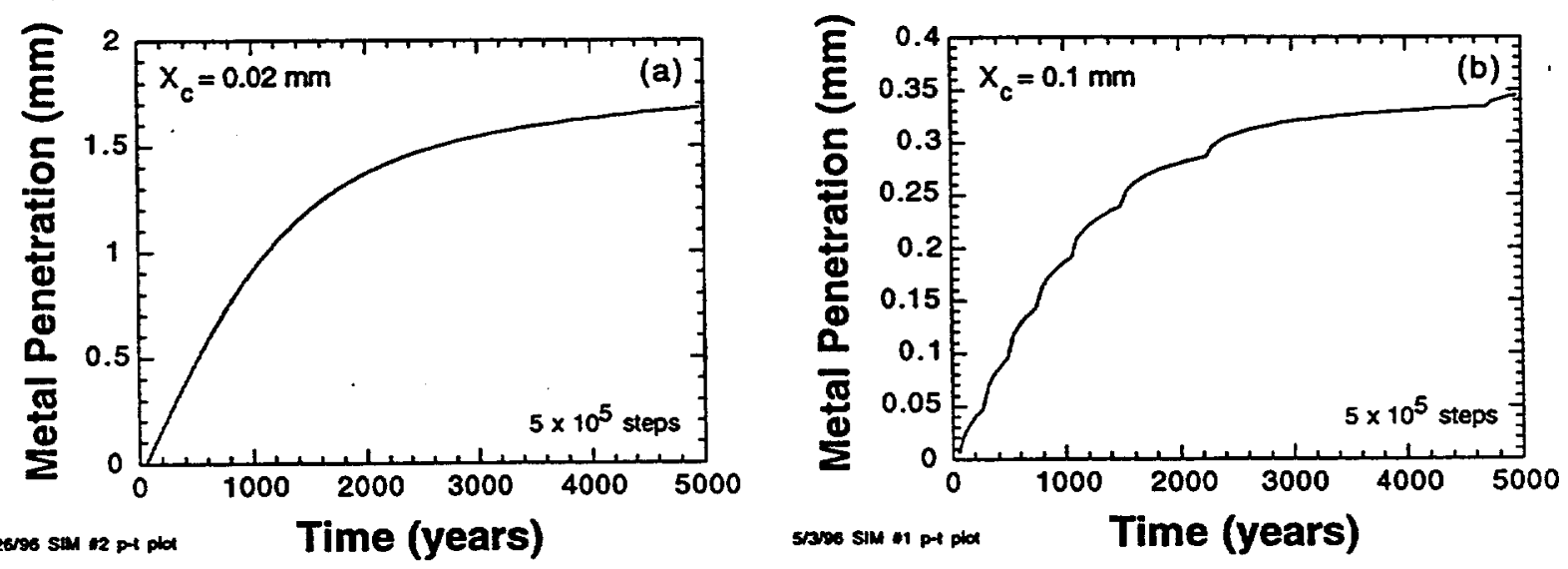

Fig. 3. Predictions of the time-dependent penetration of an iron or low-carbon steel surface subjected to the extreme temperature history shown in Fig. 2(a) and periodic spalling of the oxide at thicknesses of: (a) $x_{c}=0.02 \mathrm{~mm}$ and (b) $x_{c}=0.1 \mathrm{~mm}$.

\section{CONCLUSIONS}

Based on calculations using the physically-based model presented here, dry oxidation is not expected to significantly degrade the performance of thick, corrosion allowance barriers constructed of low-carbon steel. This conclusion remains valid when a very conservative thermal history is combined with conservative values of the activation energy and preexponential factor in the oxidation rate equation, or with a conservative model of the effects of oxide damage. However, it is suggested that the activation energy and pre-exponential constants 
used in these calculations be confirmed experimentally at the expected waste package surface temperatures of $323-533 \mathrm{~K}\left(50-260^{\circ} \mathrm{C}\right)$. Further studies should also be conducted to consider internal oxidation and the effects of water vapor in the atmosphere.

\section{ACKNOWLEDGMENTS}

This work was performed under the auspices of the U. S. DOE under contract no. W-7405-ENG48 at Lawrence Livermore National Laboratory. The support of the Yucca Mountain Site Characterization Project is gratefully acknowledged.

\section{REFERENCES}

1. D. Stahl and J. K. McCoy, "Impact of Thermal Loading on Waste Package Material Performance," in Scientific Basis for Nuclear Waste Management XVIII, Materials Research Society, Pittsburgh, PA, pp. 671-678 (1995).

2. J. K. McCoy, "Updated Report on RIP/YMMM Analysis of Designs," Report prepared for. the U.S. Dept. of Energy, Yucca Mountain Site Characteriztion by TRW Environmental Safety Systems, Inc., Report BBA000000-01717-5705-00002 REV 02 (1995).

3. N. Birks and G. H. Meier, Introduction to High Temperature Oxidation of Metals, Edward Amold, London (1983).

4. R. B. Runk and H. J. Kim, Oxidation of Metals 2, 285 (1970).

5. D. Caplan and M. Cohen, Corr. Sci. 6, 321 (1966).

6. E. J. Caule, K. H. Buob, and M. Cohen, J. Electrochem. Soc. 108, 829 (1961).

7. O. Kubaschewski and B. E. Hopkins, Oxidation of Metals and Alloys, Academic Press, London, p. 108-110 (1962).

8. M. H. Davies, M. T. Simnad and C. E. Birchenall, J. Metals 3, 889 (1951).

9. W. E. Boggs and R. H. Kachik, J. Electrochem. Soc. 116, 424 (1969).

10. G. E. Forsythe, M. A. Malcolm and C. B. Moler, Computer Methods for Mathematical Computations, Prentice-Hall, Englewood Cliffs, New Jersey (1977).

11. T. A. Buscheck, J. J. Natao and S. F. Saterlie, in High Level Radioactive Waste Management: Proceedings of the Fifth International Conference, ANS, La Grange Park, IL and ASCE, New York, pp. 592-610 (1994). 


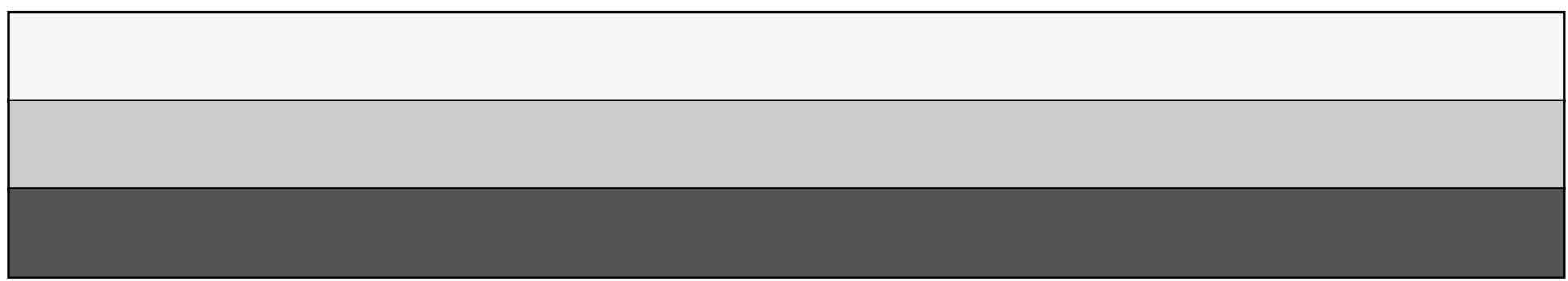

